(2) Open Access Full Text Article

ORIGINAL RESEARCH

\title{
Knowledge, Practice, and Associated Factors of Nurses in Pre-Hospital Emergency Care at a Tertiary Care Teaching Hospital
}

This article was published in the following Dove Press journal: Open Access Emergency Medicine

\section{Hailemichael Abate Chilot Mekonnen (D)}

Department of Medical Nursing, College of Health Science, Gondar, Ethiopia
Correspondence: Hailemichael Abate Email haie206k@gmail.com
Background: Pre-hospital emergency care is a medical care given to patients before arrival in the hospital after activation of the emergency team. Poor knowledge and practice about pre-hospital emergency care hurt the health outcomes of the patients.

Objective: This study aimed to assess knowledge and practice nurses at the University of Gondar Compressive Specialized Hospital, Northwest Ethiopia.

Methods: An institutional-based cross-sectional study was conducted from March 20 to April 10, 2020. A stratified sampling technique was used to select the study participants. Data were collected using a pretested structured self-administered questionnaire. Data were analyzed using SPSS version 20. To explain study variables, frequency tables and percentages were used. Logistic regression analysis was used to see the association between independent and dependent variables.

Results: Out of the total 378 respondents, less than half (42.9\%) had good knowledge; similarly, $49.5 \%$ of them had good practice about pre-hospital emergency care. Male sex and attend formal training were significant associations with both knowledge and practice of prehospital emergency nursing care. Male participants (adjusted odds ratio (AOR) $=6.57,95 \%$ confidence interval (CI) (3.79-11.36)) and having training (AOR=1.74, 95\% CI (1.83-3.66)) were significantly associated with knowledge of pre-hospital emergency care, whereas male sex $(A O R=1.73,95 \%$ CI (1.09-2.73)) and having training (AOR=6.16, 95\% CI (2.69-14.10)) were significantly associated with the practice of pre-hospital emergency care.

Conclusion: Knowledge and practice of nurses regarding pre-hospital emergency care was found to be inadequate as compared to previous studies. Male sex and attend formal training showed a positive and significant association with both knowledge and practice of prehospital emergency nursing care. The responsible body ought to allow professional development and attending formal training for nurses.

Keywords: pre-hospital emergency care, knowledge, nurses, practice

\section{Background}

Pre-hospital emergency care is a medical care given to patients before arrival in hospital after activation of an emergency team. ${ }^{1}$ According to the global report 2017, nearly 4.5 million people die from injuries. The incidence of pedestrian road traffic injuries was also increased by $3.31 \%$. Many people died of injuries and other several thousand who were injured might survive if they get immediate emergency care. But, many of them are left with permanent disabling consequences due to a lack of awareness of pre-hospital emergency care. ${ }^{2-4}$ 
Worldwide, more 2000 child population dies every day from easily preventable emergency causes due to lack of quality immediate pre-hospital emergency care before vital function damage. ${ }^{5}$ The studies done in low- and middleincome countries estimated that up to $54 \%$ of emergency annual death decreased due to improve pre-hospital emergency care. These studies also revealed that enhancing interdisciplinary collaboration and prioritization of the problem enhance emergency care coverage. ${ }^{6,7}$ In Africa very little is known about pre-hospital emergency nursing care. Inadequate emergency nursing care, including prehospital pain management often attributed due to lack of knowledge, lack of resources, and poor assessment skills particularly in low- and middle-income countries. ${ }^{4,8,9}$ A report of injuries in Ethiopia public health facilities of Addis Ababa indicated that $94 \%$ of intentional injuries were occurred due to interpersonal conflicts that need prehospital emergency care. ${ }^{10}$ Another evidence done in Ethiopia indicates that $54.1 \%$ of death of the total number of deaths occurred due to accidents. ${ }^{11}$ The evidence revealed that until recent years, there was a little study about knowledge and practice of specific staff called Emergency Medical Team (EMT) and still no organized recruitment guideline or formal training available in most developing countries about pre-hospital emergency care. ${ }^{12}$ Less than $10 \%$ of all violence that led to death occurred in low-income countries due to delay in the emergency care before the hospital settings. ${ }^{13}$ The evidence also suggested that the lack of information or knowledge about prehospital emergency care results in $16 \%$ dissatisfaction with the care given to the client. ${ }^{14}$

Having the knowledge and practice of nurses about pre-hospital emergency leads to handover the patient in the emergency department, to better understand the concepts of pre-hospital emergency and the patient's condition. ${ }^{15}$ It is also important for patient handling for nurses' work in pre-hospital emergency settings and providing basic life support (BLS) well in the community. ${ }^{16,17}$

The presence of less advanced technology, as well as poor knowledge and practice, might impose negative consequences on the basic life support management, patient handling, and patient' probability of survival. ${ }^{18}$ Adverse events might be occurred in Pre-hospital emergency care due to deviation from standard care, incomplete and unclear documentation. ${ }^{19,20}$ Pre-hospital emergency nursing care is attributed to factors like the working unit, educational level, working experience, and training. ${ }^{13,21-23}$ In Ethiopia at the national level, a pre- hospital comprehensive emergency medical system is practically nonexistent, but to centralize the response for emergency calls in Addis Ababa one centralized threedigit number (939) stationed at Addis Ababa Emergency Prevention and Rescue Authority. ${ }^{24}$ This call is important to handle emergency patients brought to the hospital from home or on the street or road by ambulance. This emergency calls also important in case of a disaster in Ethiopia context by incorporating multi-disciplinary health professional team including nurses. Good knowledge and practice of nurses about pre-hospital emergency care, including basic life support methods, resuscitation techniques, and transporting of a patient to a hospital are mandatory to save the life of the patient and reduce mortality. Most of the time, the curriculum of nursing is considered with inhospital emergency care.

Good knowledge and skills in emergency pre-hospital care significantly affect the quality of life of patients. Up to the investigators' knowledge, there is no research done in this kind in Ethiopia, so it can be used as the baseline information for future researchers. The findings of this study will also give important clues to health professionals, policymakers, and other concerned bodies to improve the knowledge and practice of pre-hospital emergency nursing care.

Therefore, this study was aimed to assess knowledge, practice, and its associated factors of pre-hospital emergency care among nurses at the University of Gondar Compressive Specialized Hospital, Northwest Ethiopia.

\section{Methods \\ Study Design and Period}

An institutional-based cross-sectional study was conducted among nurses working at the University of Gondar Comprehensive Specialized Hospital (UOGCSH) from March 20 to April 4/2020.

\section{Study Area}

This study was conducted at the UOGCSH). It is one of the teaching hospitals in Ethiopia, which is located in Gondar town $748 \mathrm{~km}$ northwest of Addis Ababa. The hospital was established in 1954 and provide a service for more than 7 million people, both for inpatient and outpatient department. The UOGCSH has more than 14 outpatient medical service units. According to data obtained from the UOGCSH data center, the hospital has 484 professional nurses. 


\section{Source Population}

All nurses who were worked at the University of Gondar compressive specialized hospital.

\section{Study Population}

All nurses who were worked at the UOGCSH and available during the study period.

\section{Inclusion and Exclusion Criteria}

All nurses who had work experience 6 months and above during the data collection period were included in the study, whereas nurses who had given free service and seriously ill during the data collection period were excluded.

\section{Sample Size Determination and Sampling Procedure}

The sample size was calculated by using the single population proportion formula $\mathrm{n}=\left(\mathrm{Z} \frac{\alpha}{2}\right) 2 * \mathrm{p}(1-\mathrm{p}) /(\mathrm{d}) 2$. From the formula " $n$ " denotes sample size," $\frac{\alpha}{2}$ " is the reliability coefficient of standard error at the $5 \%$ level of significance with $\mathrm{z}=1.96$, " $p$ " is proportion and " $\mathrm{d}$ " is the level of standard error. The prevalence ( $p$ ) was taken as $50 \%$ since there was no similar study conducted in Ethiopia and as well the nearby countries. By using the above values, the sample size was estimated as 383 . By assuming a $10 \%$ non-response rate, the final sample size was determined to be 422 . A stratified random sampling technique was used to select 422 nurses. The hospital departments were classified into five main strata that had nearly the same working conditions: 1) internal medicine, 2) pediatrics, 3) surgery units, 4) outpatient clinics, and 5) emergency and intensive care unit (EICU). The proportional allocation was performed to each stratum and then a simple random technique was applied to select the representative sample.

\section{Data Collection Tools and Procedures}

A self-administered questionnaire adapted from other related and published studies was used to collect data on knowledge and practice of pre-hospital emergency care. $^{13,25}$ The tool has three parts, which include sociodemographic characteristics, knowledge, and practice related questions (see supplementary file 1: Table S1). Knowledge was assessed by 10 items with answers "Yes" (1 point) and "No" ( 0 points) options. The practice, in the same way, was also assessed by 10 items with answers "Yes" (1 point) and "No" (0 points) options. Then, after the correct responses were summed up and participants who were scored the mean and above were labeled as having good knowledge, whereas participants who were scored below the mean of the score were labeled as poor knowledge about pre-hospital emergency care. In the same way, the practice was assessed by those participants who scored the mean and above were labeled as good practice, whereas participants who scored below the mean were labeled as a poor practice about pre-hospital emergency care. The reliability of the tool was assessed by Cronbach's alpha of the questionnaire and estimated as 0.76 for knowledge questions and 0.71 for practice questions. The validity of the tool was assessed by a jury of two experts in the field of emergency and their recommended modification had been done. The data were collected at the site using a pretested, translated, structured interviewer-administered questionnaire by three trained nurses in which two BSc nurses in the actual data collection one MSC nurse as supervisors. Upon the data collection, the data collector instructs the participants to fill the questionnaire independently to maintain the transmitting of information between the participants.

\section{Operational Definition}

Knowledge: Those participants who scored mean value and above among the given correctly answered knowledge questions which assessed aspects of pre-hospital emergency nursing care were labeled as having good knowledge. Those who scored below the mean value of correctly answered questions were labeled as having poor knowledge. $^{13,25}$

Practice: Those participants who scored mean value and above among the given correctly answered practice questions which assessed aspects of pre-hospital emergency nursing care were labeled as having good practice. Those who scored below the mean value of correctly answered practice questions were labeled as having poor practice. ${ }^{13,25}$

\section{Data Quality Control}

To maintain data quality, a pretest was done on $22(5 \%)$ nurses at the Debark hospital. A structured intervieweradministered questionnaire was used to collect the data. Based on the finding, the questionnaire was assessed and modified in a clear context. The data were checked for its completeness during the data collection, entry, and analysis process. The completed questionnaire for missed values 
and incomplete data considered as nonresponse and discarded before data entry.

\section{Data Processing and Analysis}

The collected data were checked for its completeness and entered in the Epi info version 7. The data were exported to the Statistical Package for Social Science (SPSS) version 20 software for analysis. The data were then re-coded, cleaned with appropriate statistical analysis using SPSS. Descriptive statics such as the frequency and percentage was used. Tables and graphs were used to describe the sample characteristics and response to questionnaire items. The missing data were handled by imputation (giving code) in which replacing the missing data with certain values. Model fitness was checked by using the Hosmer-Lemeshow goodness of fit test $(p=0.52)$ and interpreted as a model fitted. All variables fulfilled the chisquare assumption and checked its odds ratio. Multicollinearity was cheeked using the variance inflation factor (VIF) and its values lie between 1 and 10, which is interpreted as no multicollinearity. Bivariable and multivariate logistic regression analysis was used to identify associated factors. The backward selection process was used to see the final associated variables. Those variables with a p-value less than 0.05 with a $95 \%$ confidence interval were considered as significantly associated with outcome variables.

\section{Results}

\section{Socio-Demographic Characteristics}

Among 422 study participants, 378 (90\%) participated in the study with a 90\% response rate. More than half 197 (52.1\%) of the participants were female. About 191 (51.5\%) of participants were in the age group of 20 to 30 years and the mean age of participants was 30.54 ( $\mathrm{SD} \pm 4.83$ ). More than half of the participants $195(51.6 \%)$ were single. Regarding the educational level majority, 337 (89.2\%) had a baccalaureate degree. Concerning years of experience, more than half 249 (65.9\%) of the participant had $\geq 5$ years' experience. About 128 (24.4\%) participants were worked in the medical unit. Concerning the training related to pre-hospital emergency care, $49(12.9 \%)$ participants took the training (Table 1). Among those who took the training, $52.38 \%$ of them took advanced life support training (Table 2).

\section{Knowledge of Nurses About Pre-Hospital and Emergency Nursing Care}

The overall prevalence of poor knowledge among nurses towards pre-hospital emergency care was $42.9 \%$ with $95 \%$
Table I Socio-Demographic Characteristics of Nurses at the UOGCSH, $2020(n=378)$

\begin{tabular}{|c|c|c|c|}
\hline Variables & Category & $\mathbf{N}$ & $\%$ \\
\hline \multirow[t]{4}{*}{ Age (years) } & $20-29$ & 191 & 51.5 \\
\hline & $30-39$ & 155 & 41 \\
\hline & $40-49$ & 32 & 8.5 \\
\hline & $\begin{array}{l}\text { Mean/SD of age } \\
\text { in years }\end{array}$ & $\begin{array}{l}30.54 \\
\text { (mean) }\end{array}$ & $\begin{array}{l} \pm 4.83 \\
\text { SD }\end{array}$ \\
\hline \multirow[t]{2}{*}{ Sex } & Male & 197 & 52.1 \\
\hline & Female & 181 & 47.9 \\
\hline \multirow[t]{3}{*}{ Marital status } & Single & 195 & 51.6 \\
\hline & Married & 162 & 42.9 \\
\hline & Divorced & 21 & 5.6 \\
\hline \multirow[t]{5}{*}{ Working unit } & EICU & 33 & 8.7 \\
\hline & Surgical unit & 77 & 20.4 \\
\hline & Medical unit & 128 & 33.9 \\
\hline & OPD & 50 & 13.2 \\
\hline & Pediatrics unit & 90 & 23.8 \\
\hline \multirow[t]{3}{*}{ Educational level } & Diploma & 16 & 4.2 \\
\hline & $\begin{array}{l}\text { Baccalaureate } \\
\text { degree }\end{array}$ & 337 & 89.2 \\
\hline & Mater and above & 25 & 6.6 \\
\hline \multirow[t]{3}{*}{ Experience } & $<5.5$ years & 212 & 56.1 \\
\hline & $5.5-10.5$ years & 139 & 36.8 \\
\hline & $\geq 10.5$ years & 27 & 7.1 \\
\hline \multirow{2}{*}{$\begin{array}{l}\text { Current working unit } \\
\text { experience }\end{array}$} & $<1.5$ years & 129 & 34.1 \\
\hline & $\geq 1.5$ years & 249 & 65.9 \\
\hline \multirow[t]{2}{*}{ Ever taking training } & Yes & 49 & 12.9 \\
\hline & No & 329 & 87.1 \\
\hline
\end{tabular}

Abbreviations: EICU, emergency and intensive care unit; OPD, outpatient department; SD, standard deviation; UOGCSH, University of Gondar Comprehensive Specialized Hospital.

CI (37.8-47.6). The majority of the participants $(76.2 \%$, 77.0\%) knew about basic life support and how cardiopulmonary resuscitation (CPR) is performed, respectively. Among the total participants more than half, 228 (60.3\%) knew how can independently manage emergency patients. Among the total participants, only 159 (42.1\%) of them knew training related to the aspects of Pre-hospital emergency care (Table 3). 
Table 2 Type of Training Taken About Pre-Hospital Emergency Care Among Nurses Working at the UOGCSH, $2020(n=378)$

\begin{tabular}{|l|l|l|}
\hline \multirow{2}{*}{ Type Training } & \multicolumn{2}{|l|}{ Frequency } \\
\cline { 2 - 3 } & Yes & No \\
\cline { 2 - 3 } & N (\%) & N (\%) \\
\hline Advanced life support & $198(52.4)$ & $180(47.6)$ \\
\hline Neonatal resuscitation & $63(16.7)$ & $31583.3)$ \\
\hline Mechanical ventilation & $27(7.1)$ & $351(92.9)$ \\
\hline CPR & $27(7.1)$ & $351(92.9)$ \\
\hline EMS & $36(9.5)$ & $542(90.5)$ \\
\hline Disaster medicine & $27(7.1)$ & $351(92.9)$ \\
\hline
\end{tabular}

Abbreviations: CPR, cardiopulmonary resuscitation; EMS, emergency medica service; UOGCSH, University of Gondar Comprehensive Specialized Hospital.

\section{The Practice of Nurses About Pre-Hospital and Emergency Care}

The overall prevalence of poor knowledge among nurses towards pre-hospital emergency care was $49.5 \%$ with $95 \%$ CI (44.4-54.2). The majority of the participants (289 (76.5\%)) well provided cardiopulmonary resuscitation (CPR) to patients. More than half of the percipients (221 (58.5\%)) well gave adequate basic life support (BLS) for patients who come to hospitals/clinics by ambulance. Less than half of the participants (160 (42.3\%)) were sent to training camp related to pre-hospital emergency care (Table 4).

\section{Factors Associated with the Knowledge of Nurses' About Pre-Hospital Emergency Care}

In the present study sex, marital status, working unit, educational level, current working unit experience, and ever-taking training were found to have significant and independently associated with knowledge of nurses about pre-hospital emergency care. In this study, the odds of having good knowledge was 6.57 times more likely (AOR $=6.57,95 \%$ CI (3.79-11.36)) in male than female participants. Working in the EICU had the odds of 3.64 times more likely $(\mathrm{AOR}=3.64,95 \% \mathrm{CI}(1.18-10.16))$ to have good knowledge as compared to working in the pediatrics unit. Having a master's and above educational level had the odds of 6.04 times (AOR=6.04 95\% CI (1.13-31.16)) more to have good knowledge as compared with diploma holders. The current working unit experience of above 1 year had the odds of 2.65 times $(\mathrm{AOR}=2.65,95 \%$ CI 1.67-4.18) more to have good
Table 3 Knowledge of Pre-Hospital Emergency Care Among Nurses at the UOGCSH, $2020(n=378)$

\begin{tabular}{|c|c|c|}
\hline \multirow[t]{2}{*}{ Questions } & Yes & No \\
\hline & $\mathbf{N}(\%)$ & $\mathbf{N}(\%)$ \\
\hline $\begin{array}{l}\text { Do you hear about pre-hospital emergency care } \\
\text { during undergraduate? }\end{array}$ & $\begin{array}{l}219 \\
(57.9)\end{array}$ & $\begin{array}{l}159 \\
(42.1)\end{array}$ \\
\hline $\begin{array}{l}\text { Do you take courses/training about pre-hospital } \\
\text { emergency care after the completion of your } \\
\text { education? }\end{array}$ & $\begin{array}{l}194 \\
(51.3)\end{array}$ & $\begin{array}{l}184 \\
(48.7)\end{array}$ \\
\hline $\begin{array}{l}\text { Do you know about basic life support/advanced } \\
\text { life support? }\end{array}$ & $\begin{array}{l}288 \\
(76.2)\end{array}$ & $\begin{array}{l}90 \\
(23.8)\end{array}$ \\
\hline $\begin{array}{l}\text { Do you know how CPR (cardiopulmonary } \\
\text { resuscitation) is performed? }\end{array}$ & $\begin{array}{l}291 \\
(77.0)\end{array}$ & $\begin{array}{l}87 \\
(23.0)\end{array}$ \\
\hline $\begin{array}{l}\text { Do you know about RTS (Revised Trauma Scale) } \\
\text { for the prognosis of injury patients? }\end{array}$ & $\begin{array}{l}185 \\
(48.9)\end{array}$ & $\begin{array}{l}193 \\
(51.1)\end{array}$ \\
\hline $\begin{array}{l}\text { Do you know training related to aspects of pre- } \\
\text { hospital emergency nursing care? }\end{array}$ & $\begin{array}{l}159 \\
(42.1)\end{array}$ & $\begin{array}{l}219 \\
(57.9)\end{array}$ \\
\hline $\begin{array}{l}\text { Do you know the recommended methods of } \\
\text { transportation of emergency cases according to } \\
\text { the distance between the site of trauma and the } \\
\text { health-care facility? }\end{array}$ & $\begin{array}{l}211 \\
(55.8)\end{array}$ & $\begin{array}{l}167 \\
(44.2)\end{array}$ \\
\hline $\begin{array}{l}\text { Do you know the components of pre-hospital } \\
\text { emergency ambulance carry? }\end{array}$ & $\begin{array}{l}190 \\
(50.3)\end{array}$ & $\begin{array}{l}187 \\
(49.5)\end{array}$ \\
\hline $\begin{array}{l}\text { Do you know how you can independently manage } \\
\text { an emergency patient? }\end{array}$ & $\begin{array}{l}228 \\
(60.3)\end{array}$ & $\begin{array}{l}150 \\
(39.7)\end{array}$ \\
\hline $\begin{array}{l}\text { Do you know the ways you respond if you get } \\
\text { suspected acute Myocardial Infarction? }\end{array}$ & $\begin{array}{l}198 \\
(52.4)\end{array}$ & $\begin{array}{l}180 \\
(47.6)\end{array}$ \\
\hline \multicolumn{3}{|l|}{ The overall level of knowledge } \\
\hline Good & $\begin{array}{l}162 \\
(42.9)\end{array}$ & \\
\hline Poor & $\begin{array}{l}216 \\
(57.1)\end{array}$ & \\
\hline
\end{tabular}

Abbreviation: UOGCSH, University of Gondar Comprehensive Specialized Hospital.

knowledge compared with less than 1 year. Having training related to pre-hospital emergency care had the odds 1.74 times (AOR=1.74, 95\% CI (1.83-3.66)) more to have good knowledge as compared with its counterparts (Table 5).

\section{Factors Associated with the Practice of Nurses' About Pre-Hospital Emergency Care}

In a multivariable regression analysis, five variables sex, marital status, educational level, experience, having 
Table 4 Practice of Pre-Hospital Emergency Care Among Nurses at the UOGCSH, $2020(n=378)$

\begin{tabular}{|c|c|c|}
\hline \multirow[t]{2}{*}{ Questions } & Yes & No \\
\hline & $\mathbf{N}(\%)$ & $\mathbf{N}(\%)$ \\
\hline $\begin{array}{l}\text { Do you give adequate basic life support (BLS) for } \\
\text { patients who come to your hospitals/clinics by } \\
\text { ambulance? }\end{array}$ & $\begin{array}{l}221 \\
(58.5)\end{array}$ & $\begin{array}{l}157 \\
(41.5)\end{array}$ \\
\hline $\begin{array}{l}\text { Do you provide cardio-pulmonary resuscitation } \\
\text { (CPR) to patients? }\end{array}$ & $\begin{array}{l}289 \\
(76.5)\end{array}$ & $\begin{array}{l}87 \\
(23.0)\end{array}$ \\
\hline $\begin{array}{l}\text { Do you attend lectures/courses/seminars about } \\
\text { pre-hospital management/emergency and critical } \\
\text { care }\end{array}$ & $\begin{array}{l}203 \\
(53.7)\end{array}$ & $\begin{array}{l}173 \\
(45.8)\end{array}$ \\
\hline $\begin{array}{l}\text { Do you confidently deliver A B C D E in the care } \\
\text { of the emergency patient? }\end{array}$ & $\begin{array}{l}240 \\
(63.5)\end{array}$ & $\begin{array}{l}138 \\
(36.5)\end{array}$ \\
\hline $\begin{array}{l}\text { Do you use protocols and algorithms for trauma/ } \\
\text { emergency patient management? }\end{array}$ & $\begin{array}{l}260 \\
(68.8)\end{array}$ & $\begin{array}{l}118 \\
(31.2)\end{array}$ \\
\hline $\begin{array}{l}\text { Do you have basic life support equipment } \\
\text { (mucous extractor, Ambu Bag, mouth-to-mouth } \\
\text { airway) with you? }\end{array}$ & $\begin{array}{l}260 \\
(68.8)\end{array}$ & $\begin{array}{l}118 \\
(31.2)\end{array}$ \\
\hline $\begin{array}{l}\text { Is your staff sent to emergency medical service } \\
\text { (EMS) training camp? }\end{array}$ & $\begin{array}{l}160 \\
(42.3)\end{array}$ & $\begin{array}{l}218 \\
(57.7)\end{array}$ \\
\hline $\begin{array}{l}\text { Is there mismanagement regarding pre-hospital } \\
\text { emergency care in your work area }\end{array}$ & $\begin{array}{l}197 \\
(52.1)\end{array}$ & $\begin{array}{l}181 \\
(47.9)\end{array}$ \\
\hline $\begin{array}{l}\text { Is CATS (centralized accident and trauma } \\
\text { services) started and effective? }\end{array}$ & $\begin{array}{l}161 \\
(42.6)\end{array}$ & $\begin{array}{l}217 \\
(57.4)\end{array}$ \\
\hline $\begin{array}{l}\text { Do you present on an accident site and } \\
\text { participated in managing? }\end{array}$ & $\begin{array}{l}179 \\
(47.4)\end{array}$ & $\begin{array}{l}199 \\
(52.6)\end{array}$ \\
\hline \multicolumn{3}{|l|}{ Prevalence of overall practice } \\
\hline Good & $\begin{array}{l}191 \\
(50.5)\end{array}$ & \\
\hline Poor & $\begin{array}{l}187 \\
(49.5)\end{array}$ & \\
\hline
\end{tabular}

Abbreviation: UoGCSH, University of Gondar Comprehensive Specialized Hospital.

training were found to have significantly associated with the practice of nurse in pre-hospital emergency care. In the present study, the odds of good practice was 1.7 times more likely $(\mathrm{AOR}=1.73,95 \%$ CI (1.09-2.73)) in male than that of female participants. The odds of good practice in married marital status was 1.64 times (AOR=1.64 95\% CI (1.01-2.68)) than that of single marital status. For respondents who had between 5 and 10 years of experience, the odds of good practice were 2.63 times $(\mathrm{AOR}=2.63,95 \% \mathrm{CI}(1.12-7.35))$ than that of less than
5 -year experience. For participants who had taken the training, the odds of good practice was 6.16 times $(\mathrm{AOR}=6.16,95 \% \mathrm{CI}(2.69-14.10))$ than who had not taken the training (Table 6).

\section{Discussion}

In this study, the overall prevalence of good knowledge was found to be $42.9 \%$ with $95 \%$, CI $(37.8-47.6)$. The finding was lower than the studies conducted in South Africa $(51.7 \%),{ }^{21}$ Nepal $(52 \%),{ }^{26}$ Sweden $(71 \%),{ }^{27}$ Brazil $(83.2 \%),{ }^{28}$ and Iran $(72.2 \%) .{ }^{29}$ The finding also lower than the studies done in Iran $(61 \%),{ }^{30}$ India $(69 \%),{ }^{23}$ and other two similar studies in India $(48 \%),{ }^{13}$ and $(52 \%)^{25}$ of knowledge questions. This discrepancy might be due to the training gap related to pre-hospital emergency care, education level participants, and working exposure in the emergency area, and the difference in the health-care system. ${ }^{31-33}$

In this study majority of the participants $(76.2 \%, 77.0 \%)$ knew about basic life support and cardiopulmonary resuscitation (CPR) respectively. This finding was supported by the study done in Saudi Arabia. ${ }^{34}$ This study also showed that about $60.3 \%$ knew how can independently manage emergency patients. This finding was supported by the study done in Rwanda. ${ }^{35}$ The possible explanation might be due to knowledge of the aspects of pre-hospital emergency care is essential for better patient care. ${ }^{36}$

In a multivariable regression analysis, being male was found to be nearly seven times more to be knowledgeable about pre-hospital emergency as compared with its counterparts. This finding was inconsistent with the study done in Iran. ${ }^{29}$ The possible explanation might be because males are more exposed to different sociocultural and social activities than females in the Ethiopian context. Furthermore, females have extraordinary activities as compared with males such as cocking, washing, and preparing for daily home consumption. ${ }^{37}$ Therefore, they might have less time to read and scale up their knowledge by far.

Working in the ICU unit was found to be 3.64 times more likely to have good knowledge as compared with working in the pediatrics unit. This finding was supported by the study conducted in South Africa ${ }^{22}$ and Iran. ${ }^{29}$ The possible explanation might be because of the prevalence of violence and none violence causality emergency cases occurred more in adults than the pediatric age group. ${ }^{38}$ Therefore, those nurses working in the adult emergency unit might have more exposure to pre-hospital emergency care than the pediatric unit. 
Table 5 Factors Associated with Knowledge of Nurses About Pre-Hospital Emergency Care at the UOGCSH, 2020 ( $n=378$ )

\begin{tabular}{|c|c|c|c|c|}
\hline \multirow[t]{3}{*}{ Variables } & \multicolumn{2}{|l|}{ Knowledge } & \multirow[t]{3}{*}{ COR } & \multirow[t]{3}{*}{ AOR } \\
\hline & Good & Poor & & \\
\hline & $\mathbf{N}(\%)$ & $\mathbf{N}(\%)$ & & \\
\hline \multicolumn{5}{|l|}{ Sex } \\
\hline Male & $119(31.5)$ & $78(20.6)$ & $4.89(3.13,7.64)$ & $6.57(3.79,11.36)^{* *}$ \\
\hline Female & $43(11.4)$ & $138(36.5)$ & 1 & 1 \\
\hline \multicolumn{5}{|l|}{ Working unit } \\
\hline EICU & $26(6.9)$ & $7(4.9)$ & $4.44(1.75,|I| .27)$ & $3.46(1.18,10.16)^{*}$ \\
\hline Surgical & $23(6.1)$ & $54(14.3)$ & $0.5 I(0.27,0.97)$ & $0.53(0.25, I .13)$ \\
\hline Medical & $58(15.3)$ & $70(18.5)$ & $0.99(0.57,1.70)$ & $1.37(0.72,2.62)$ \\
\hline OPD & $14(3.7)$ & $36(9.5)$ & $0.47(0.22,0.98)$ & $0.33(0.13,0.82)^{*}$ \\
\hline Pediatrics unit & $42(11.1)$ & $49(12.9)$ & 1 & 1 \\
\hline \multicolumn{5}{|l|}{ Educational level } \\
\hline Diploma & $4(1.1)$ & $12(3.2)$ & 1 & 1 \\
\hline Baccalaureate degree & $142(37.6)$ & $195(5 \mid .5)$ & $2.17(0.69,6.91)$ & $2.1 \mathrm{I}(0.57,7.78)$ \\
\hline Mater and above & $16(4.2)$ & $9(2.4)$ & $5.33(1.32,21.53)$ & $6.04(1.13,32.16)^{*}$ \\
\hline \multicolumn{5}{|c|}{ Current working experience } \\
\hline$<$ lyear & $36(9.5)$ & $93(24.6)$ & I & I \\
\hline$\geq$ lyear & $129(33.9)$ & $123(32.5)$ & $2.82(1.59,4.97)$ & $2.65(1.67,4.18)^{* *}$ \\
\hline \multicolumn{5}{|l|}{ Ever taking training } \\
\hline Yes & $27(7.2)$ & $15(3.9)$ & $2.68(1.37,5.23)$ & $1.74(1.83,3.66)^{*}$ \\
\hline No & 135 (35.7) & $201(53.2)$ & I & I \\
\hline
\end{tabular}

Notes: *Statistically significant ( $\mathrm{p}$-value $<0.05)$, **statistically highly significant ( $\mathrm{p}$-value $<0.0 \mathrm{I}$ ).

Abbreviations: AOR, adjusted odds ratio; COR, crude odds ratio; EICU, emergency and intensive care unit; OPD, outpatient department; UOGCSH, University of Gondar Comprehensive Specialized Hospital.

The participants' level of education was found to be significantly associated with good knowledge of prehospital emergency care. In this regard, having a master's and above educational level was found to be 6.04 times more to have good knowledge as compared with diploma holders. This finding was supported by the study conducted in South Africa ${ }^{22}$ and Iran. ${ }^{29}$ The possible explanation might be because as the level of education increased the same for the knowledge through reading and gaining experience from learning. ${ }^{39,40}$

The current working unit experience of above 1 year was found to be nearly three times more to have good knowledge compared with less than 1 year. The finding was supported by the studies conducted in South
Africa. ${ }^{21,22,29}$ The possible explanation could be because the more the exposure to a particular works the more the knowledge. $^{41}$

The participants who took training related to prehospital emergency care were found to be 1.74 times to have good knowledge than those who had not taken the training. This finding was in line with the study done in South Africa, ${ }^{21,22}$ in Nepal ${ }^{26}$ and Indonesia. ${ }^{13,23}$ The possible explanation might be due to that training can enhance an individual's body of knowledge. ${ }^{42}$

In this study, $49.5 \%$ of the participants had good practice about pre-hospital emergency care. This result was in line with the studies done in India (50\% of the poor practice). ${ }^{23}$ The finding also supported by other two similar studies 
Table 6 Factors Associated with the Practice of Nurses About Pre-Hospital Emergency Care at the UOGCSH, 2020 ( $\mathrm{n=378)}$

\begin{tabular}{|c|c|c|c|c|}
\hline \multirow[t]{3}{*}{ Variables } & \multicolumn{2}{|l|}{ Practice } & \multirow[t]{3}{*}{ COR } & \multirow[t]{3}{*}{ AOR } \\
\hline & Good & Poor & & \\
\hline & $\mathbf{N}(\%)$ & $\mathbf{N}(\%)$ & & \\
\hline \multicolumn{5}{|l|}{ Sex } \\
\hline Male & $110(29.1)$ & $87(23.1)$ & I.7I (I.I4,2.56) & $1.73(1.09,2.73)^{*}$ \\
\hline Female & $77(20.3)$ & $104(27.5)$ & 1 & I \\
\hline \multicolumn{5}{|l|}{ Marital status } \\
\hline Single & $89(23.5)$ & $106(28)$ & I & 1 \\
\hline Married & $86(22.8)$ & $76(20.1)$ & $1.35(0.88,2.05)$ & $1.64(1.01,2.68)^{*}$ \\
\hline Divorced & $12(3.2)$ & $9(2.4)$ & $1.58(0.64,3.94)$ & $\mathrm{I} .44(0.49,4.20)$ \\
\hline \multicolumn{5}{|l|}{ Educational level } \\
\hline Diploma & $5(1.3)$ & II (2.9) & 1 & 1 \\
\hline Baccalaureate degree & $165(43.6)$ & $172(45.5)$ & $2.1 I(0.72,6.2 I)$ & $\mathrm{I} .8 \mathrm{I}(0.57,5.69)$ \\
\hline Mater and above & $17(4.6)$ & $8(2.1)$ & $4.67(1.21,18.04)$ & $4.05(0.94,17.47)^{*}$ \\
\hline \multicolumn{5}{|l|}{ Experience } \\
\hline$<5$ years & III (29.4) & I0I (26.7) & 1 & I \\
\hline $5-10$ years & $55(14.6)$ & $84(22.2)$ & $0.59(0.38,1.92)$ & $0.47(0.28,1.78)$ \\
\hline$\geq 10$ years & $21(3.5)$ & $6(1.6)$ & $3.18(1.23,8.21)$ & $2.63(1.12,7.35)^{*}$ \\
\hline \multicolumn{5}{|l|}{ Ever taking training } \\
\hline Yes & $41(10.3)$ & $8(0.8)$ & $6.42(2.92,14.13)$ & $6.16(2.69,14.10)^{* *}$ \\
\hline No & 146 (39.2) & $183(49.7)$ & 1 & I \\
\hline
\end{tabular}

Notes: *Statistically significant ( $\mathrm{p}$-value $<0.05$ ), **statistically highly significant ( $\mathrm{p}$-value $<0.0 \mathrm{I})$.

Abbreviations: AOR, adjusted odds ratio; COR, crude odds ratio; UOGCSH, University of Gondar Comprehensive Specialized Hospital.

done in India (46\%) and (54\%) respectively. ${ }^{13,25}$ However, it was lower than the study done in Sweden in which $70 \%$ of the participants had a good practice. ${ }^{27}$ The possible explanation might be because there are huge socio-demographic variations between Ethiopia and Sweden by far. As it is known practice of a certain aspect in our case pre-hospital emergency care could be affected by the knowledge level as per participants' level of specialty. This is to mean participants in Sweden were degree and above holders as compared with the Ethiopian in which most were diploma and degree holders.

In this study, majority $76.5 \%$ of the participants well provided cardiopulmonary resuscitation (CPR) to patients. This finding was supported by the study done in Tanzania. ${ }^{43}$ The possible explanation might be due to the skill of an individual can improve the practice aspects of pre-hospital emergency care. ${ }^{27}$
In a multivariable logistic regression analysis, variables like sex, marital status, educational level, experience, having training were found to have significantly associated with the practice of nurses in pre-hospital emergency nursing care. Being male was found to be nearly two times more to have good practice as compared with its counterparts. Although there is no clear evidence which supports this finding, possible justifications might be females have extraordinary activities as compared with male such as cocking, washing and preparing for daily home consumptions. Furthermore, females might have decreased social contact after their work time since they have a lot to do in the Ethiopian context. ${ }^{37}$ However, to get married was 1.64 times more likely to have good practice as compared with being single. The possible explanation might be those pairs would probably have better-shared information and minimized attention divert 
as compared with being single. Besides, married healthcare professionals might be satisfied in their work than that of a single one. ${ }^{44}$

The participants having greater than 10 years of experience were 2.63 times more the odds of good practice than less than 5 years' experience. This finding was supported by the studies conducted in South Africa. ${ }^{21,22,29}$ The possible explanation could be because of the more exposure to a particular work the more the knowledge. ${ }^{41}$

Ever took training about pre-hospital emergency nursing care was found to be nearly six times more likely to have good practice as compared with its counterparts. This finding was supported by the study conducted in India. ${ }^{23}$ The possible explanation might be since those having training might have a greater chance of scaling up their knowledge and practice as compared with did not take it. ${ }^{42}$

\section{Strength and Limitation of the Study}

This study was new in Ethiopia, which is used as a baseline for the coming researchers. The limitation of this study was due to the lack of similar studies to make a more comparative discussion. Recall bias was another limitation in this study because of the self-reporting of the questionnaire by participants. The participants also might respond only to socially acceptable answers. The crosssectional nature of the study cannot rule out the causeeffect relationship.

\section{Implications for Nurse in Pre-Hospital Emergency Care}

Education and training resulting in knowledge and practice are important for nurses in pre-hospital emergency care. This is especially important for acute and life-threatening emergency patients' where decision-making and care activities are performed under time pressure. This research shows the nurses who had training and a higher level of education have a good performance in pre-hospital emergency care. Strengthen supportive training and exposure to emergency care can have its own implication on health policy, to change practice and better patient care as a whole.

\section{Conclusions}

The finding of this study showed that more than half of the participants had a poor magnitude of knowledge and practice about pre-hospital emergency care as compared to most of the previous studies. Having higher educational level, male sex, working unit in EICU, more experience in current working unit and having training showed a positive and significant association with poor knowledge, whereas male sex, married marital status, experience and attending formal training were found to be associated poor practice of pre-hospital emergency care. In-service training related to the health conditions and the time needed to care for the patient is important for better pre-hospital emergency care. Enhancing individual-level education and work exposure in emergency care enable better performance to prehospital emergency care. The researcher better carryout multicenter studies to address the problem in a wider context. Further study by using triangulated study design to rule out the factors and to formulate standards and guidelines related to pre-hospital and emergency nursing care.

\section{Abbreviations}

PR, cardiopulmonary resuscitation; BLS, basic life support; EICU, emergency and intensive care unit; EMS, emergency medical service; EMT, emergency medical team; OPD, outpatient department; UOGCSH, University Gondar Comprehensive Specialized Referral Hospital; USA, United States of America.

\section{Data and Material Availability}

The raw data is available from the corresponding authors on rational request, and the summary data are available on the main document.

\section{Ethical Approval and Consent}

The study was performed based on the ethical standards of put down the declaration of Helsinki. Ethical clearance was obtained from the institutional ethical review committee of the school of nursing and college of health science of University Gondar with ethical clearance letter reference number of Rf.No:S/N2012/123/2012. An official permission letter was obtained from the University of Gondar hospital administration. After understanding the purpose of the study, written informed consent was obtained from study participants. Confidentiality of participants' information was kept.

\section{Consent to Publication}

Not applicable.

\section{Acknowledgment}

Our deepest gratitude goes university of Gondar for all expenses of this research work and study participants 
participated in the research. The authors also would like to give great appreciation to data collectors and supervisors for their contribution to this paper.

\section{Author Contributions}

All authors made a significant contribution to the work reported, whether that is in the conception, study design, execution, acquisition of data, analysis, and interpretation, or in all these areas; took part in drafting, revising, or critically reviewing the article; gave final approval of the version to be published; have agreed on the journal to which the article has been submitted; and agree to be accountable for all aspects of the work.

\section{Funding}

The study was supported by the University of Gondar College of medicine and health science. The funding does not have a further role in the design, data collection, analysis, drafting, manuscript, preparation, and publication of this paper.

\section{Disclosure}

The authors report no conflicts of interest in this work.

\section{References}

1. Wilson MH, Habig K, Wright C, Hughes A, Davies G, Imray CH. Prehospital emergency medicine. Lancet. 2015;386(10012):2526-2534. doi:10.1016/S0140-6736(15)00985-X

2. James SL, Castle CD, Dingels ZV, et al. Global injury morbidity and mortality from 1990 to 2017: results from the global burden of disease study 2017. Injury Prevention. 2020;26:196-i114. doi:10.1136/injuryprev-2019-043494

3. Khan MA, Grivna M, Nauman J, et al. Global incidence and mortality patterns of pedestrian road traffic injuries by sociodemographic index, with forecasting: findings from the global burden of diseases, injuries, and risk factors 2017 Study. Int J Environ Res Public Health. 2020;17 (6):2135. doi:10.3390/ijerph17062135

4. Lourens A, Parker R, Hodkinson P. Prehospital acute traumatic pain assessment and management practices in the Western Cape, South Africa: a retrospective review. Int $J$ Emerg Med. 2020;13:1-10. doi:10.1186/s12245-020-00278-w

5. Sleet DA. The Global Challenge of Child Injury Prevention. Multidisciplinary Digital Publishing Institute; 2018.

6. Moresky RT, Razzak J, Reynolds T, et al. Advancing research on emergency care systems in low-income and middle-income countries: ensuring high-quality care delivery systems. BMJ Global Health. 2019;4(Suppl 6):e001265. doi:10.1136/bmjgh-2018-001265

7. Lecky FE, Reynolds T, Otesile O, et al. Harnessing inter-disciplinary collaboration to improve emergency care in low-and middle-income countries (LMICs): results of research prioritization setting exercise. BMC Emerg Med. 2020;20(1):1-10. doi:10.1186/s12873-020-00362-7

8. Kironji AG, Hodkinson P, De Ramirez SS, et al. Identifying barriers for out of hospital emergency care in low and low-middle income countries: a systematic review. BMC Health Serv Res. 2018;18(1):291. doi:10.1186/s12913-018-3091-0
9. Mehmood A, Rowther AA, Kobusingye O, Hyder AA. Assessment of pre-hospital emergency medical services in low-income settings using a health systems approach. Int J Emerg Med. 2018;11(1):53. doi:10.1186/s12245-018-0207-6

10. Wolde A, Abdella K, Ahmed E, et al. Pattern of injuries in Addis Ababa, Ethiopia: a one-year descriptive study. East Central African J Surgery. 2008;13(2):14-22.

11. Tsegaye F, Abdella K, Ahmed E, Tadesse T, Bartolomeos K. Pattern of fatal injuries in Addis Ababa, Ethiopia: a one-year audit. East Central African J Surgery. 2010;15(2):10-17.

12. Ismail S, Zia N, Samad K, et al. Prehospital airway management in emergency and trauma patients: a cross-sectional study of ambulance service providers and staff in a low-and middle-income country. Prehosp Disaster Med. 2015;30(6):606-612. doi:10.1017/S1049023X15005385

13. Plummer V, Boyle M. Knowledge, attitude, and practice of ambulance nurses in prehospital care in Malang, Indonesia. Australasian Emergency Care. 2018;21(1):8-12. doi:10.1016/j.auec.2017.12.001

14. Larsson G, Strömberg U, Rogmark C, Nilsdotter A. Patient satisfaction with prehospital emergency care following a hip fracture: a prospective questionnaire-based study. BMC Nurs. 2018;17(1):38. doi:10.1186/s12912-018-0307-x

15. Sanjuan-Quiles Á, Del Pilar Hernández-Ramón M, Juliá-Sanchis R, García-Aracil N. Handover of patients from prehospital emergency services to emergency departments: A qualitative analysis based on experiences of nurses. J Nurs Care Qual. 2019;34(2):169. doi:10.1097/NCQ.0000000000000351

16. de Schoutheete J, Hachimi Idrissi S, Watelet J-B. Pre-hospital interventions: introduction to life support systems. B-ENT. 2016;12(26/ 1):41-54.

17. Soren S, Linda W, Veronica L. Development of the pre-hospital emergency care, the registered nurses' role in the ambulance service—a swedish perspective. Emergency Med. 2016;6:1.

18. Crewdson K, Rehn M, Lockey D. Airway management in prehospital critical care: a review of the evidence for a 'top five' research priority. Scand J Trauma Resusc Emerg Med. 2018;26 (1):1-6. doi:10.1186/s13049-018-0556-4

19. Hagiwara MA, Magnusson C, Herlitz J, et al. Adverse events in prehospital emergency care: a trigger tool study. BMC Emerg Med. 2019;19(1):14. doi:10.1186/s12873-019-0228-3

20. Kamphausen A, Roese H, Oechsle K, et al. Challenges faced by prehospital emergency physicians providing emergency care to patients with advanced incurable diseases. Emerg Med Int. 2019;2019:2019. doi:10.1155/2019/3456471

21. Butler MW, Adefuye AO. Assessing the knowledge of emergency medical care personnel in the Free State, South Africa, on aspects of paediatric pre-hospital emergency care. Pan Afr Med J. 2019;32:32. doi:10.11604/pamj.2019.32.98.17718

22. Mothibi JD, Jama M, Adefuye AO. Assessing the knowledge of emergency medical care practitioners in the Free State, South Africa, on aspects of pre-hospital management of psychiatric emergencies. Pan Afr Med J. 2019;33:33. doi:10.11604/ pamj.2019.33.132.18426

23. Nandasena G, Abeysena C. Knowledge, attitudes and skills of doctors, nurses and emergency medical technicians in pre-hospital care and emergency medicine who accompany patients in ambulances which arrive at the National Hospital of Sri Lanka. Int J Clin Anesthesia Research. 2018;2:038-043. doi:10.29328/journal.ijcar.1001010

24. Sultan M, Abebe Y, Tsadik AW, Ababa A, Yesus AG, MouldMillman N-K. Trends and barriers of emergency medical service use in Addis Ababa; Ethiopia. BMC Emerg Med. 2019;19(1):28. doi:10.1186/s12873-019-0242-5

25. Kumar S, Agarwal AK, Kumar A, Agrawal G, Chaudhary S, Dwivedi V. A study of knowledge, attitude and practice of hospital consultants, resident doctors and private practitioners with regard to pre-hospital and emergency care in Lucknow. Indian J Surgery. 2008;70(1):14-18. doi:10.1007/s12262-008-0003-2 
26. Roshana S, Batajoo K, Piryani R, Sharma M. Basic life support: knowledge and attitude of medical/paramedical professionals. World j Emergency Medicine. 2012;3(2):141. doi:10.5847/wjem.j.issn.19208642.2012.02.011

27. Abelsson A, Lindwall L, Suserud B-O, Rystedt I. Ambulance nurses' competence and perception of competence in prehospital trauma care. Emerg Med Int. 2018;2018. doi:10.1155/2018/5910342

28. Oliveira AC, Marziale MHP, Paiva MHRS, Lopes ACS. Knowledge and attitude regarding standard precautions in a Brazilian public emergency service: a cross-sectional study. Revista Da Escola De Enfermagem Da USP. 2009;43(2):313-319. doi:10.1590/S008062342009000200009

29. Asadi P, Ziabari SMZ, Vatani J, Ghotbi J, Safaee F. Assessing the knowledge of Guilan Pre-Hospital emergency personnel (EMS) from safety principles. J Adv Pharmacy Education Res. 2019;9(S2):99.

30. Lalehgani H, Yadollahi S, Fadaee Y, Ansari F, Karimifard M. Knowledge of emergency medical service staff on crisis management. Iranian J Emergency Medicine. 2018;5:3.

31. Lee-Jayaram JJ, Kunimune M, Hara KM, Barnes LC, Berg BW. Pediatric simulation training for emergency pre-hospital providers in hawai ' $\mathrm{i}$ : an inter-professional curriculum collaboration and update. Hawai J Health Social Welfare. 2020;79(5 Suppl 1):13.

32. Lindskou TA, Mikkelsen S, Christensen EF, et al. The Danish prehospital emergency healthcare system and research possibilities. Scand J Trauma Resusc Emerg Med. 2019;27(1):100. doi:10.1186/ s13049-019-0676-5

33. Bashiri A, Savareh BA, Ghazisaeedi M. Promotion of prehospital emergency care through clinical decision support systems: opportunities and challenges. Clinical Experimental Emergency Med. 2019;6 (4):288. doi:10.15441/ceem.18.032

34. Saquib SA, Al-Harthi HM, Khoshhal AA, et al. Knowledge and attitude about basic life support and emergency medical services amongst healthcare interns in university hospitals: a cross-sectional study. Emerg Med Int. 2019;2019:2019. doi:10.1155/2019/9342892

35. Nshutiyukuri C, Bhengu BR, Gishoma D. An assessment of Nurses' knowledge, attitude and practice of emergency care related to road traffic accident victims at three selected hospitals in Rwanda. African $J$ Emergency Med. 2020;10:127-131. doi:10.1016/j.afjem.2020. 03.003
36. Phukubye TA, Mbombi MO, Mothiba TM. Knowledge and practices of triage amongst nurses working in the emergency departments of rural hospitals in limpopo Province. Open Public Health J. 2019;12:1. doi:10.2174/1874944501912010439

37. Dessalegn M, Ayele M, Hailu Y, et al. Gender inequality and the sexual and reproductive health status of young and older women in the afar region of ethiopia. Int J Environ Res Public Health. 2020;17 (12):4592. doi:10.3390/ijerph17124592

38. Ballesteros MF, Williams DD, Mack KA, Simon TR, Sleet DA. The epidemiology of unintentional and violence-related injury morbidity and mortality among children and adolescents in the United States. Int J Environ Res Public Health. 2018;15(4):616. doi:10.3390/ ijerph15040616

39. Darling-Hammond L, Flook L, Cook-Harvey C, Barron B, Osher D. Implications for educational practice of the science of learning and development. Appl Dev Sci. 2020;24(2):97-140. doi:10.1080/ 10888691.2018.1537791

40. McMahon WW, Oketch M. Education's effects on individual life chances and on development: an overview. British J Educational Studies. 2013;61(1):79-107. doi:10.1080/00071005.2012.756170

41. Dickens GL, Ion R, Waters C, Atlantis E, Everett B. Mental health nurses' attitudes, experience, and knowledge regarding routine physical healthcare: systematic, integrative review of studies involving 7549 nurses working in mental health settings. BMC Nurs. 2019;18 (1):16. doi:10.1186/s12912-019-0339-x

42. Lee YLA, Malik A, Rosenberger III PJ, Sharma P. Demystifying the differences in the impact of training and incentives on employee performance: mediating roles of trust and knowledge sharing. J Knowledge Management. 2020;24:1987-2006. doi:10.1108/JKM-04-2020-0309

43. Kaihula WT, Sawe HR, Runyon MS, Murray BL. Assessment of cardiopulmonary resuscitation knowledge and skills among healthcare providers at an urban tertiary referral hospital in Tanzania. BMC Health Serv Res. 2018;18(1):935. doi:10.1186/s12913-018-3725-2

44. Gedif G, Sisay Y, Alebel A, Belay YA. Level of job satisfaction and associated factors among health care professionals working at University of Gondar Referral Hospital, Northwest Ethiopia: a cross-sectional study. BMC Res Notes. 2018;11(1):824. doi:10.1186/ s13104-018-3918-0

\section{Publish your work in this journal}

The Open Access Emergency Medicine is an international, peerreviewed, open access journal publishing original research, reports, editorials, reviews and commentaries on all aspects of emergency medicine. The manuscript management system is completely online and includes a very quick and fair peer-review system, which is all easy to use. Visit http://www.dovepress.com/testimonials.php to read real quotes from published authors. 